\title{
Direito Commercial
}

\author{
LITTERALIDADE DO 'TITULO DE CREDITO
}

(Capitulo III do livro “Titulos ao Portador”, em preparação)

94) - O titulo de credito é sempre litteral, o que quer dizer - não ha titulo de credito sem documento assignado pelo devedor. Este requisito da litteralidade foi creado como o meio essencial de garantir a facilidade e segurança da circulação, e tem como consequencia que o devedor não é obrigado a mais, nem o credor pode ter outros direitos senão aquelles declarados no titulo. A litteralidade dos titulos está declarada no Cod. Civil, art. 1508.

95) - Isto, porém, não quer dizer que o direito de credito esteja incorporado no titulo. Quer apenas dizer que o direito de credito não pode ser exercido sem a exhibição do titulo. Os titulos de credito pertencem áquella classe de documentos que Brunner chama dispositivos, isto é que constituem e dão fundamento ao direito documentado.

96) - Que o direito não está incorporado no titulo de oredito, se verifica da propria lei, que prevê o caso do possuidor do titulo o perder, e providencia para a tutella do direito do possuidor, nessa hypothese. Assim é que a lei 2044, nos arts. 36 e seguintes providencia sobre os direitos do portador da cambial, que tenha sido destruida ou extraviada. Egualmente, o art. 1509 do Cod. Civil providencia sobre egual hypothese em relação aos titulos ao portador, 
auctorisando até o emissor a emittir novos titulos em substituição dos reclamados. Essa disposição demonstra cathegoricamente que pelo nosso Codigo o titulo de credito não incorpora o direito de credito a elle correspondente, pois que, se assim fosse, só poderiam ser emittidos novos titulos na hypothese unica de terem sido destruidos os titulos anteriores.

97) - O nosso direito distingue, portanto, entre o proprietario do titulo de credito e o seu simples possuidor. 0 primeiro tem a propriedade, direito que não se contém no titulo, mas está fora deste. $\mathrm{O}$ segundo tem a posse, direito que se contém no titulo. E' o recht am papier e o recht aus dem papier, dos allemães. O direito do portador ou possuidor, ainda que de má fé, é o de receber a prestação que quizer pagar o devedor. O direito, porém, de exigir essa prestação só compete ao legitimo credor, ao legitimo proprietario do titulo de credito.

98) - Em garantia da facilidade e segurança da circulação dos titulos de credito, a lei estabeleceu que o devedor teria o direito de pagar a qualquer portador, ainda que não auctorisado a dispôr do titulo, ficando, em virtude desse pagamento exonerado da obrigação correspondente ao titulo, sempre que o pagamento não tiver sido feito de má fé, isto é, com o intuito de prejudicar ao legitimo credor. O direito, porém, de reclamar o pagamento só compete ao portador auctorisado a dispôr do titulo, diz o artigo 1505 do Cod. Civil, isto é, ao legitimo proprietario ou seu representante.

99) - Fica assim bem discriminada a propriedade da simples posse dos titulos de credito, o que bem demonstra que, pelo nosso direito, o titulo de credito não incorpora $o$ direito á prestação n'elle declarada, porque então nesse caso só o portador é que teria o direito de exigir o pagamento dessa prestação.

100) - Em garantia da circulação dos titulos, a lei exonerou o emissor da obrigação de verificar a boa fé do por- 
tador, e quanto aos titulos cambiaes, da obrigação de verificar a authenticidade dos endossos (lei 2044, art. 4..$^{\circ}$. Mas, quando o devedor tiver noticia da má fé do portador, ou fôr notificado para não fazer o pagamento, poderá, apesar d'isso, fazel-o, ficando exonerado de toda responsabilidade?

101) - A questão é muito discutida entre os escriptores allemães. (Saleilles, Theorie de l'obligation, nota ao numero 279). A nós parece preferivel a opinião que reconhece em tal caso a responsabilidade do emissor, principalmente diante das disposições do Cod. Civil, arts. 521 e 1509, que separam evidentemente o direito de credito do titulo de credito, negando assim que este incorpore a obrigação n'elle declarada, e valha por si só, como a moeda.

102) - Verifica-se, portanto, que a nossa theoria legal é a theoria da propriedade, a eigenthumstheorie dos allemães, pela qual a propriedade do titulo segue a propriedade do credito, e não a propriedade do credito acompanha a posse do titulo, como sustentam os partidarios da doutrina unilateral. Se assim fosse, o portador de má fé teria o direito de exigir o pagamento da prestação, e contra elle o emissor não teria o direito de oppôr a excepção de dólo.

103) - Mas do art. 1507 do Cod. Civil se deduz claramente que a inopponibilidade das excepcões só garante o portador de bôa fé, sendo licito, portanto, ao emissor arguir a má fé do portador, sempre que ella chegar ao seu conhecimento.

104) - Como se estabelece, porém, a bôa fé do portador, e quaes são os direitos que ella confere? Basta a acquisição com bôa fé para attribuir o dominio dos titulos de credito? Em relação aos titulos cambiaes parece não haver duvida, pois que o art. 39, $\S 2$.' da lei 2044, dispõe expressamente que só no caso de má fé na acquisição o portador poderá ser obrigado a abrir mão do titulo.

105) - Em relação, porém, aos titulos ao portador já não se dá o mesmo, pois que o art. 521 do Cod. Civil con- 
fere ao legitimo proprietario o direito de reivindicar os titulos que houver perdido ou que lhe houverem sido furtados, ainda mesmo do poder de um portador de bôa fé. E' evidente, portanto, que nesse caso a acquisição com bôa fé não confere o dominio dos titulos.

106) - Comparando-se, portanto, os arts. 521, 1506 e 1507 do Cod. Civil, temos que, quando o terceiro de bôa fé adquirir os titulos do ladrão ou do inventor, tendo sido os titulos furtados ao emissor ou perdidos por este, a acquisição será perfeita, bastando n'esse caso a bôa fé do adquirente para lhe conferir o dominio. Sempre, porém, que ns titulos houverem sido perdidos por um legitimo proprietario ou a este furtados, já a acquisição com bôa fé do terceiro não será sufficiente para lhe conferir o dominio dos titulos comprados, pois que a lei garante ao legitimo proprietario desapossado o direito de reivindicar os seus titulos, direito que nega ao emissor, quando é este a victima da perda ou furto.

107) - Porque a propriedade do dono dos titulos merece da lei melhor protecção que a do emissor? Ou em outros termos, porque a bôa fé do adquirente, em se tratando de titulos perdidos pelo emissor ou a este furtados, merece da lei melhor protecção que a de um outro adquirente, quando se trata de titulos perdidos por um outro proprietario ou a este furtados?

108) - E' uma contradicção flagrante da lei e impossivel de ser satisfactoriamente explicada. Se a acquisição com bôa fé não basta para conferir dominio, não deverá ser considerado legitimo adquirente o comprador de titulos perdidos pelo emissor ou a este furtados. Se ao contrario, essa acquisição com bôa fé é sufficiente para attribuir dominio, não se comprehende que o proprietario dos titulos perdidos ou furtados conserve o direito de os reivindicar do adquirente de bôa fé.

109) - Em um e outro caso o adquirente foi levado a comprar os titulos pela negligencia do emissor ou do pro- 
prietario em os guardar. Porque essa negligencia é punida pela lei, quando parte do emissor, e não é, quando parte do proprietario?

110) - Dir-se-á que, quando o terceiro compra titulos furtados ao emissor ou perdidos por este, a lei o protege, com o fim de garantir a facilidade e circulação dos titulos de credito. Mas, porque, em se tratando de titulos furtados ou perdidos pelo proprietario, a circulação dos titulos já não merece do legislador a mesma attenção?

111) - E' evidente a injustiça da reivindicação concedida ao proprietario desapossado, pelo art. 521 do Cod. Civil. O principio verdadeiro é aquelle pelo qual basta $a$ acquisição com bôa fé para conferir dominio, sempre que se trate de compra e venda de quaesquer bens moveis. $\mathrm{E}^{\prime}$ o unico principio capaz de garantir a facilidade e segurança da circulação dos bens moveis, sem as quaes o commercio é impossivel.

112) - A litteralidade dos titulos de credito consiste em que o devedor não é obrigado a pagar senão á vista do titulo, e que o credor não pode exigir a prestação senão apresentando o titulo. Ao portador de bôa fé o devedor só poderá oppôr excepção baseada em nullidade interna ou externa do titulo, além das defesas pessoaes que tiver contra o portador.

113) - Contra o terceiro portador de bôa fé, não poderá, portanto, jámais o devedor allegar defesa alguma extranha ao titulo. Contra o sacador, porém, dos titulos cambiaes poderá o devedor allegar toda e qualquer defesa baseada na relação fundamental que deu origem ao titulo. Poderá, por exemplo, allegar que acceitou o titulo só por favor ao sacador, nada devendo, de facto, a este. A questão será de prova. Se o devedor provar satisfactoriamente que acceitou o titulo por méro favor ao sacador, terá provado que o titulo é nullo por falta de causa, não encerrando, portanto, obrigação alguma juridica do acceitante em 
consequencia da qual deva este pagar a prestação declarada no titulo.

114) - $O$ titulo de credito, portanto, para ser exigivel do devedor, é necessario que resulte de uma causa verdadeira e licita. Isto quer dizer que a obrigação deve ser real e não abstracta. A theoria da obrigação abstracta já teve o seu momento de voga, porém hoje está inteiramente posta á margem. E' mesmo admiravel que Magarinos TorRES tente resussital-a no seu livro sobre a Nota Promissoria.

115) - 0 citado escriptor diz, effectivamente, que foi a theoria da emissão que inspirou a nossa lei cambial, depois de ter inspirado a allemã. Ora, a theoria da emissão é, sem duvida alguma, uma theoria contractual, pois que a emissão é um contracto, pelo qual o devedor entrega o titulo ao primeiro portador. Se tem por base o contracto, isto é, um accordo de vontades, como se dizer que a obrigação representada pelo titulo de credito é uma obrigação abstracta?

116) - A obrigação é real e não abstracta. O que a lei permittiu, com o fim de facilitar e assegurar a circulação dos titulos, foi que nestes se fizesse abstracção da causa, dispensando que esta fosse declarada. Abstrahir, porém, da necessidade da declaração da causa não quer dizer que esta não exista. A causa existe sempre, nem pode deixar de existir.

117) - Por isso mesmo, a discussão sobre a causa da divida só é possivel entre as proprias partes contractantes, ou entre o devedor e um terceiro, se este é um portador de má fé, combinado com o primeiro portador para conseguir do pretenso devedor o pagamento de uma divida não verdadeira.

118) - Isso quer dizer que, diante de um portador de bôa fé, o devedor não pode allegar que a divida não tem causa, pois que, em relação ao portador de bôa fé, a divida tem sempre causa, que é o preço da acquisição do titulo, por elle pago. 
119) - Em relação, porém, ao primeiro portador, com o qual contractou, o devedor tem sempre o direito de allegar a falta de causa, e se conseguir proval-o satisfactoriamente, deverá ser exonerado da obrigação de pagar o titulo. Isto prova evidentemente que a divida declarada no titulo deve ser real e não abstracta.

120) - Se a obrigação contida nos titulos de credito fosse uma obrigação abstracta, o devedor não deveria ter o direito de allegar a falta de causa contra o portador immediato. Deveria ser obrigado a resgatar o titulo em qualquer hypothese. Só assim se comprehende o contracto obrigatorio abstracto, cuja creação NEUBEckER reivindica orgulhosamente para a litteratura juridica allemã nestes termos: "A nós allemães, ao povo da razão pura, do imperativo cathegorico, estava reservada a honra de crear no mundo moderno, o contracto obrigatorio abstracto, o contracto puro, o contracto cathegorico: Promisisti, solvé"!

121) - Se assim fosse, a obrigação contida nos titulos de credito seria, com effeito, uma obrigação abstracta. Desde, porém, que o devedor tem o direito de allegar qualquer defesa pessoal contra o portador do titulo, tem, sem duvida alguma, o direito de allegar que nada deve ao mesmo portador, tendo acceito o titulo por méro favor, não existindo, portanto, causa para a obrigação.

122) - Não existe, portanto, em nosso Direito obrigação abstracta, porque em relação ao portador immediato o devedor tem sempre o direito de provar a falta de causa, e mesmo em relação ao portador mediato, tem o direito de provar que elle é um portador de má fé. Só diante do portador de bôa fé é que a defesa do devedor fica circumscripta ás nullidades internas ou externas do titulo. Ora, não se comprehende que a obrigação contida no titulo de credito seja abstracta só em relação ao portador de bôa fé, e não o seja em relação aos demais portadores.

123) - Magarinos Torres argumenta com o art. 43 da lei 2044 pelo qual o signatario da declaração cambial fica 
vinculado por essa assignatura, ainda no caso da falsidade, falsificação ou nullidade de qualquer outra assignatura. 0 argumento é improcedente, porque a disposição citada visa apenas proteger o portador de bôa fé. Ora, em relação a este, a obrigação do devedor não é abstracta, mas tem uma causa real, que é o preço da acquisição do titulo, pago pelo portador de bôa fé. Pouco importa que esse preço não tenha sido recebido pelo devedor. Acceitando um titulo á ordem, ou emittindo um titulo ao portador, o devedor sabia que assignava um titulo destinado a circular, susceptivel, portanto, de cahir nas mãos de um portador de má fé, o qual o poderia passar adiante. Ficou, portanto, obrigado a pagar a qualquer portador de bôa fé, ainda que este tivesse adquirido o titulo de um portador de má fé. A não ser assim, tornava-se impossivel a circulação dos titulos de credito.

124) - O titulo de credito é, portanto, formal ou litteral, isto é, só é exigivel pela sua forma, pelo contheúdo da prestação n'elle declarada, e sem a sua exhibição o devedor não pode ser obrigado ao pagamento. Uma vez perdido ou extraviado, só mediante ordem judicial, o devedor póde ser constrangido ao pagamento, ou a entregar novos titulos (lei 2044, art. 36, § 4. ${ }^{\circ}$, Cod. Civil, art. 1509, $\S$ unico).

125) - O devedor não é vinculado por uma assignatura no titulo, e sim pela obrigação que este representa. Se fosse vinculado pela simples assignatura, independentemente da existencia de qualquer obrigação, não poderia arguir contra o portador de má fé a falta de direito de exigir a prestação, assim como no caso de inutilisação, perda ou extravio do titulo, não poderia ser obrigado a pagar por ordem judicial, nem a emittir novos titulos. Desapparecido o titulo, teria tambem desapparecido o vinculo obrigacional. Se este vinculo subsiste mesmo após o perecimento do titulo, é que elle não está no titulo, mas fóra do titulo, na relação de direito que prende o devedor ao credor.

126) - Se o titulo de credito não declara a sua causa, nem por isso deixará sempre de ter uma causa, pois não 
ha acto humano que não tenha uma causa determinante. 0 titulo de credito não declara a sua causa, não porque represente uma obrigação abstracta, mas simplesmente para facilitar e garantir a segurança de sua circulação, excluindo d'entre os successivos portadores toda e qualquer discussão sobre a causa.

127) - Quanto aos titulos ao portador, não é só a dêclaração da causa que é omittida no titulo como tambem o nome do credor. E' que é da essencia d'esses titulos fazer o devedor abstracção do nome do credor. A obrigação romana só podia se estabelecer entre o devedor e um credor determiñado. A obrigação moderna se estabelece sempre entre duas pessôas, mas dessas duas pessôas só ha necessidade de se determinar uma: a do devedor. A pessôa do credor é indifferente, o elemento patrimonial da obrigação dominou inteiramente o elemento pessoal. Desde que no vencimento o titulo surja nas mãos de uma pessôa qualquer de bôa fé, essa pessôa será o credor, a quem o devedor será obrigado a pagar a prestação declarada no titulo. E' a theoria da emissão abstracta defendida por Arcangeli, no seu livro sobre Titulos de credito. Emissão abstracta não quer dizer que não haja emissão, e sim simplesmente que o devedor, ao fazer a emissão, faz abstracção do nome do credor.

128) - O titulo de credito é, portanto, litteral, neste sentido - que, embora representando uma relação juridica existente fóra d'elle, o acto juridico não está perfeito emquanto o titulo não está assignado pelo devedor e entregue ao credor. $O$ titulo de credito, portanto, não prova apenas a divida a que se refere, mas é essencial para que essa divida adquira vigor juridico, nos termos declarados no titulo. N'isso se distingue dos titulos meramente probatorios, isto é, que têm por fim apenas provar a divida a que se referem.

\section{DR. OCTAVIO MENDES}

(Prof. cathedratico de Direito Commercial) 